\title{
A COMUNICAÇÃO PESSOAL NA DINÂMICA DIGITAL APRENDENTE COMO CONTRIBUIÇÃO PARA O PLANEJAMENTO E DESENVOLVIMENTO
}

\section{PERSONAL COMMUNICATION IN LEARNING DIGITAL DYNAMICS AS CONTRIBUTION TO PLANNING AND DEVELOPMENT}

\author{
Manuel Sousa Pereira ${ }^{1}$ \\ António Cardoso ${ }^{2}$
}

\section{RESUMO}

A comunicação é um processo dinâmico, em permanente mutação e evolução, não linear, intrínseca ao próprio homem, pois é a forma de exteriorizar, partilhar, comungar comportamentos, atitudes, sentimentos, ideias, opiniões, e, dessa forma, obter feedback dos receptores, e, assim, orientar novamente a comunicação para a compreensão mútua, que é o principal objetivo da comunicação. A partir dos anos 1990 entramos na era da individualização dos media, na qual cada pessoa pode participar na construção de informações e pode ser um todo comunicativo. No entanto, as novas formas de comunicação têm como suporte uma base tecnológica capaz de estabelecer de forma interactiva, participativa e rápida, fomentando a participação e a interacção de uns para com os outros, bem como o uso mais eficaz da participação e intenção junto da comunidade. A comunicação eletrônica e digital é cada vez mais uma excelente forma de comunicar, já que é eficiente em termos de velocidade de processamento, facilidade de utilização e ainda é extremamente econômica, pois basta ter dois computadores ligados à Internet para comunicar da forma que achar mais conveniente. $\mathrm{O}$ objetivo deste trabalho consiste numa reflexão teórica e conceitual sobre o papel da comunicação pessoal na dinâmica aprendente dos indivíduos enquanto elementos comunicantes que interagem com o todo comunicacional.

Palavras-chave: Comunicação pessoal. Interatividade comunicacional. Dinâmica aprendente.

\begin{abstract}
Communication is a dynamic, constantly changing and evolving, non-linear, intrinsic to man himself, therefore is how to externalize, share, commune, behaviors, attitudes, feelings, ideas, opinions, and thus obtain feedback receptor, and thus guide the communication again for mutual understanding, which is the main objective of communication. From 90s entered the age of individualization of the media, where each person can participate in the construction of information and be a communicative whole. However, new forms of communication is supported by a technological base capable of establishing interactive, participatory and quickly by encouraging participation and interaction toward each other, as well as the most effective use of participation and intention in the community. The electronic and digital communication besides being increasingly an excellent way of communicating, because it is efficient in terms of processing speed, ease of use and to be extremely economic because, just have two computers connected to the Internet to communicate the way they find most convenient. The aim of this work is a theoretical and Conceptual reflection on the role of personal communication in learner dynamics of individuals while connecting elements that interact with the whole communication.
\end{abstract}

Keywords: Personal communication. Communicative interaction. Learner dynamics.

\footnotetext{
${ }^{1}$ School of Business Studies - Instituto Poliutécnico de Viana do Castelo. Praça General Barbosa, 4900-347, Viana do Castelo, Portugal. E-mail: msousa.manuel@gmail.com

${ }^{2}$ Assistant Professor na University Fernando Pessoa. Coordinator of Bachelor and Masters Degrees in Business Sciences. Coordinator of MBA in Business Sciences. Coordinator of Bachelor in Management and Accounting. Praça 9 de Abril 349, 4249 004 Porto, Portugal. E-mail: ajcaro@ufp.edu.pt
} 


\section{Introdução}

A comunicação é um processo dinâmico, em permanente mutação e evolução, não linear, intrínseco ao próprio homem, pois é a forma de exteriorizar, partilhar, comungar comportamentos, atitudes, sentimentos, ideias, opiniões, e, dessa forma, obter feedback dos receptores, e, assim, orientar novamente a comunicação para a compreensão mútua, que é o principal objetivo da comunicação. O acto comunicativo é inato ao próprio homem, pois a nossa apresentação, a imagem, o cabelo, a forma de olhar, a forma de sentir, de estar, a respiração, é comunicar. Embora a comunicação eficaz aconteça quando o feedback (retorno da informação) é oferecido corretamente, na medida em que o que se transmite seja sinônimo do que realmente se transmitiu. $\mathrm{O}$ aspecto fundamental do processo comunicativo reside no fato de os intervenientes na comunicação se entenderem mutuamente. Para que isso aconteça é necessário ser bom observador, e escutar convenientemente o interlocutor, descobrir suas reais necessidades, desejos e aspirações, estabelecer uma linguagem assertiva, interpretar as suas mensagens, perceber o contexto e as circunstâncias dessa mesma comunicação e ganhar a confiança, estando sempre atento ao retorno da informação.

$\mathrm{O}$ ato de comunicar é inato ao homem, pois incorpora a forma como nos apresentamos. A nossa imagem - o cabelo, a forma de olhar, a forma de sentir e de estar e mesmo a nossa respiração - é um ato comunicacional.

A comunicação só pode ser considerada eficaz quando se registra feedback (retorno da informação), o que significa que a mensagem enviada inicialmente foi recebida de forma correta pelo receptor.

$\mathrm{O}$ aspeto fundamental do processo comunicativo reside no fato de os intervenientes na comunicação se entenderem mutuamente. Para que isso aconteça é necessário ser bom observador e escutar convenientemente o interlocutor, descobrir as suas reais necessidades, desejos e aspirações, estabelecer uma linguagem assertiva, interpretar suas mensagens, perceber o contexto e as circunstâncias dessa mesma comunicação e ganhar a confiança, estando sempre atento ao retorno da informação.

A definição de comunicação como "a transmissão de informação, ideias, emoção, habilidades, etc., pelo uso de símbolos - palavras, imagens, números, gráficos, etc." avançada por Littlejohn (1988, p. 37) na obra Fundamentos teóricos da 
comunicação humana, e acrescentando ainda que essas emissões são "o ato ou processo de transmissão que usualmente se designa como comunicação", é uma enunciação que reportamos para o nosso estudo como assertiva. Através dessa definição podemos verificar a necessidade de estabelecer uma relação com alguém, de transmitir algo através da palavra, de sons, de gestos, e, ao levar a cabo qualquer uma dessas ações, estamos, certamente, comunicando.

Neste ensaio, procuraremos analisar o papel da comunicação pessoal na dinâmica digital aprendente, baseando-nos num conjunto de autores de referência nessa área, sobre os quais fazemos um conjunto de considerações na aprendizagen organizacional.

\section{Evolução dos formatos comunicacionais (breve resenha histórica)}

Na década de 1990 houve a privatização dos canais de televisão em Portugal, como podemos verificar nas seguintes palavras de Sousa e Santos (2003, p. 10)

[...] Em 1990, a Assembleia da República aprovou a Lei da Televisão que previa a existência de operadores privados e, no ano seguinte, foi aberto o concurso. No meio de uma enorme controvérsia sobre o processo de atribuição de frequências, Cavaco Silva decidiu atribuir em 1992 - duas frequências de televisão nacionais: uma à Sociedade Independente de Comunicação (SIC), liderada por Pinto Balsemão e outra à Televisão Independente (TVI), um canal de inspiração cristã, então associado à Igreja Católica.

Essa privatização e o desenvolvimento de novas formas de financiamento específico do setor da comunicação social através da publicidade e do patrocínio vão-se assistindo a uma especialização do saber cada vez mais crescente para satisfazer necessidades, e sobretudo na cada vez mais exigida qualidade de serviços a prestar.

A televisão é um instrumento de hipnose coletiva, como flash fotográfico da sociedade, na medida em que consegue abranger um todo social e dele consegue falar, segundo o entendimento de Kerckhove (1997, p. 39), "em primeiro lugar, ao corpo e não à mente. [...] o ecrã de vídeo tem um impacte tão directo sobre o meu sistema nervoso e as minhas emoções, e tão pouco efeito sobre a mente".

A televisão interativa é aquela em que podemos assistir a uma pluralidade de informação, a um leque alargado de programas de entretenimento, e sobretudo a uma alta definição em termos de imagem. 
Em termos de discurso televisivo passamos do oficial para o informal, do formal para o menos solene, do mais pedagógico para o mais natural.

Podemos verificar que desde a década de 1960-70 até hoje tem-se verificado que a sociedade em geral passou de uma cultura de massas, na qual a mesma mensagem era "consumida" por pelo maior número de pessoas a uma cultura do efêmero, da velocidade, do consumo imediato, da satisfação do momento. Nessa perspectiva, assiste-se, hoje, a um crescente controle sobre a realidade, a uma personalização e individualização dos fatos, das interfaces, por exemplo, a construção de interfaces, tal como indica Negroponte, (1996, p. 109): “[...] falar, apontar, e olhar deveriam funcionar em conjunto enquanto parte de um interface multimodal, menos baseado em trocas de mensagens nos dois sentidos".

$\mathrm{Na}$ vertente tecnológica, sobre o computador pessoal, Negroponte (1996, p. 55) diz: "O crescimento dos computadores pessoais está a acontecer tão rapidamente que a futura televisão de arquitectura aberta é o PC, ponto final. [...] Um livro possui uma apresentação com elevado contraste, é leve, é fácil de folhear e não é muito caro. Mas fazê-lo chegar a si inclui o transporte e a armazenagem [...]". Assim e continuando o pensamento: “[...] Os livros digitais nunca se esgotam”. Uma selecção de públicos e de segmentos de mercado ou "públicos-alvo" a que interessa cada vez mais satisfazer necessidades individuais e pessoais.

Assistimos, cada vez mais, a um uso individualizado dos meios eletrônicos, ou seja, a possibilidade de cada pessoa em particular ter a própria programação televisiva, em que poderá construir o seu jornal, ser o realizador do próprio filme, de sua música preferida, a existência ou não de publicidade, e se a desejar poder construir uma panóplia de spots publicitários vocacionados para a satisfação dos seus interesses, o seu documentário, a seu interface televisivo.

Em termos comunicacionais, podemos observar que emissor e receptor, cada vez mais, assumem o comando da própria comunicação, ou seja, o receptor toma posição sobre as matérias e visiona; em outras palavras o receptor passa a ser ator e entra em cena, contracenando com os vários autores desse "palco". 
O sistema televisivo, movido por interesses econômicos, assume posições demasiado superficiais sobre a realidade, não aprofundando os temas, e revelando apenas partes do todo social, transpondo naturalmente apenas uma parte dessa realidade.

Os meios de comunicação baseiam-se na característica moda total, assim como na indumentária. A publicidade, na interpretação de Lipovetsky (1983, p. 145),

Como a publicidade, a moda nada diz, é uma estrutura vazia, por isso é um erro ver nela uma forma moderna do mito. O imperativo da moda não é narrar ou fazer sonhar, mas mudar, mudar por mudar e a moda só existe através deste processo de desqualificação incessante das formas.

$\mathrm{Na}$ vida política, econômica, na alteração das mentalidades (ideológica), na comunicação de espectáculo, os media caracterizam-se fundamentalmente na inovação dos meios de comunicação, na captação do efêmero, na sedução contínua, procurando conquistar as audiências. Ou seja, os media funcionam de acordo com as leis do mercado, indo constantemente à procura da satisfação do seu público "consumidor" (oferta e procura), sendo seu objetivo primeiro maximizar o lucro.

\section{A comunicação na ótica pessoal}

Essa individualização comunicional como qualquer novo paradigma transporta consigo aspectos positivos, mas também novos problemas e desafios comunicacionais. Segundo Dezanove (1997, p. 283):

Seguramente, o mais importante efeito da fotografia da Terra é expandir a percepção que temos do nosso e eu para além da imagem do corpo e alargar o nosso sentido de identidade. Na verdade, desde o primeiro momento em que vemos essa fotografia, tomamos posse da Terra e de um novo poder para nela investir. É uma extensão dos meus olhos. Tudo o que nela está contido é "meu" tanto quanto eu sou "dela".

Assim, assistimos hoje a uma mudança estrutural no nível da comunicação, na medida em que o processo comunicativo é cada vez mais concebido à medida de cada pessoa em particular, com suas particularidades, satisfazendo seus desejos, suas aspirações e suas necessidades mais profundas. Daí, que a televisão do futuro será mais um "mergulho individual" sobre os temas, matérias, jogos, os quais apenas seus intervenientes manuseiam e controlam. 
Os meios de comunicação social, hoje, constroem um conjunto de sensações, emoções, sentimentos coletivos, os quais as pessoas apenas aceitam sem questionar, criam imaginários coletivos sobre a realidade. Dessa forma, mesmo com as tecnologias da comunicação, é necessário um esforço acrescido, pois não se chega separar o acessório do essencial, é preciso ser criativo e inovador na plataforma individual de perceber o mundo e, assim, ser mais ativo e menos reativo perante a realidade.

Na perspectiva de Dezanove (1997, p. 283): “Com o advento da Internet temos o primeiro meio que é oral e escrito, privado e público, individual e colectivo ao mesmo tempo. A ligação entre a mente pública e a mente privada é feita através de redes abertas e conectadas do planeta”.

O computador pessoal veio individualizar a comunicação, na medida em que permitiu utilizar a escrita, a visão e a via oral para descobrir e construir nossos próprios estilos de apreensão do mundo e nossos próprios estilos para comunicar.

Como pontos positivos, no nível individual podemos apontar:

- maior rapidez comunicativa (ex.: Internet, e-mail);

- comunicação bidirecional (ex.: emissor e receptor estabelecem uma comunicação quase em tempo real);

- maior especialização do conhecimento (ex.: cada pessoa estuda mais sobre menos).

Possíveis pontos menos positivos associados:

- individualização da comunicação (ex.: perda de referências comuns que poderão originar conflitos sociais);

- mecanização comunicativa (computador como parceiro e não como instrumento de comunicação.

Um dos principais problemas que poderão intensificar-se no futuro é o da regulamentação das tecnologias da comunicação, tais como: a defesa dos direitos de autor, da violação da vida privada, da adulteração de sistemas informáticos e de software, da responsabilização, do controle das interações etc.

$\mathrm{Na}$ atualidade assistimos a um conjunto de características tecnológicas como ubiquidade, espontaneidade, bidirecionalidade, universalidade e globalização da informação que arrastam consigo novos desafios e orientações estratégicas a todos os "elos" comunicantes, sejam indíviduos, sejam organizações. Verificamos que, segundo 
Mafra (2002, p. 9): “En lo que respecta al enorme tamaño de la información, en el hombre se origina un sentimiento doble: por una parte una sensación de dominio y en sus antípodas una sensación de tremenda pequeñez”.

As novas tecnologias de informação e comunicação são cada vez mais um meio de interação, participação com o mundo que nos rodeia, através do qual é possível estar presente, participar, alterar, agindo perante uma situação específica e, dessa forma, dar uma contribuição de forma rápida e eficiente.

Com esses meios é possível estabelecer comunicação com todo o mundo, sendo apenas necessário um computador e um ou vários utilizadores, bem como um modem.

Relativamente à qualidade e ao controle das informações e comunicações, podemos verificar que existem conteúdos que apresentam credibilidade através de sites certificados por entidades reconhecidas e validadas de forma coerente com as exigências atuais de utilização da Internet, todavia, por outro lado, temos muitos sítios de moradas de Internet que não apresentam credibilidade para que possamos acreditar na informação apresentada.

O estudo de Gonzales et al. (2004) refere que uma em cada cinco pessoas utiliza a Internet para obter informações em vez de adquirir os respectivos meios de comunicação escritos em formato papel. Assim, podemos verificar que, atualmente, a Internet já pode ser considerada como um instrumento de obtenção de informação com expressividade e com a previsibilidade de que no futuro seja mais utilizada.

\section{Comunicação e interatividade}

No entanto, as novas formas de comunicação têm como suporte uma base tecnológica capaz de estabelecer de forma interativa, participativa e rápida, fomentando a participação e a interacção de uns para com os outros, bem como o uso mais eficaz da participação e intenção junto da comunidade. Segundo Besser (2004, p. 1): "During the past 2 years, ICA has been involved productively with IAMCR in co hosting boutique conferences devoted to advertising various aspects of the digital divide, traditionally defined as 'a gap between those who have access to technology and those who do not"'.

Nessa mesma linha de pensamento, Bryant (2004, p. 394) afirma que: "this has been a very positive and progressive endeavour. Issues of equity, social justice, and the 
like are embedded in the digital divide and should burn holes in our conscience until produce some of the best scholarship and action research we have to offer".

Nesse sentido, podemos verificar que nem todos os seres humanos têm acesso aos novos meios de comunicação, pois para que isso aconteça é necessário ter os meios materiais e técnicos. O que realmente acontece é que se vai construindo, dessa forma, uma desigualdade entre os povos e nações. Todavia, uma sociedade será cada vez mais ativa e participativa conforme a sua intervenção e interação com o todo social. Podemos sistematizar no entendimento de Contreras (2000, p. 60).

[...] el cambio tecnológico es un factor que altera radicalmente la base económica de los países. Por tanto, la tecnociencia tiene la capacidad de transformar la realidad social, política, cultural y económica de las sociedades contemporáneas, y lo hace a una escala global pero no igual en todos los lugares del mundo.

A tecnologia e a ciência são uma realidade contínua e continuada, capazes de alterar atitudes e comportamentos de uma forma sistemática e morosa, que acontece ao longo dos tempos, revolucionando mentalidades, introduzindo criatividades e implementando normas e procedimentos de criatividade e inovação capazes de melhorar continuamente a vivência em comum. Segundo McChesney (1993, p. 102):

This commitment to democratic communication and to journalism also provides critical communication scholars with an entrée to political activism that is unique among left academics. We are poised to work with activist groups and the public at large to help them decode the media critically, use the existing media systems to be best effect, and produce their own communications.

Dentro dos vários meios de comunicação existem diferentes formas de comunicar capazes de contribuir para a participação dos cidadãos nas atividades e acções da comunidade, contribuindo para a construção de relações pessoais duradouras com os diferentes atores da sociedade. Assim, na perspectiva de Bryant e Miron (apud Jennings, 2004, p. 391):

The primary goal of communication in Taoism and Buddhism was knowledge of the self and of the essence of the world, rather than informing and influencing others or manipulating the external word. As a consequence, communication took a "transcendental" form geared toward the eternal reality assumed to underlie all temporary events, including one's own individual existence. Such a form of communication was radically different from the transactional European type of communication. 
Os objetivos essenciais de comunicar é a partilha de algo, com a finalidade de compreender os outros e de ser compreendido. Embora além da simples transmissão e recepção de mensagens, esta pode ser utilizada para informar, influenciar os outros e manipular o mundo exterior. Nesses termos, através da comunicação eficiente, podemos contribuir para a alteração de ideias, atitudes, que podem produzir determinados comportamentos.

Mas comunicar eficientemente significa também construir a realidade, influenciando os outros pela transmissão de mensagens que vão ao encontro das necessidades humanas. O segredo da comunicação eficiente reside nos "atores sociais" enquanto indivíduos ou organizações capazes de se compreender mutuamente e gerar sinergias úteis aos indivíduos e à comunidade, tal como em Robert (1983),

[...] European tradition of the study of mass communication is an emphasis on the society, rather then the individuals in that society, as the unit of analysis. This emphasis conforms to the tradition of the social sciences, each of which is defined by the level at witch it seeks explanation: anthropology studies cultures, sociology studies groups, and psychology studies individuals, and so on. [...] in socialist countries, but it would strengthen the arguments of those who try to explain the behaviour of individuals in capitalist societies on the basis of the economic structure if they could demonstrate that tings were different in other systems.

Se, por um lado, temos uma tradição europeia que a partir da segunda metade do século XX, no nível dos estudos em comunicação de massas, tem tido o enfoque nos estudos das ciências sociais, por outro lado, temos uma vertente marxista baseada na ideia de que tudo se baseia na estrutura econômica.

\section{A comunicação eletrônica e digital aprendente}

A comunicação eletrônica e digital é cada vez mais uma excelente forma de comunicar, já que é eficiente em termos de velocidade de processamento, facilidade de utilização e é extremamente econômica, pois basta ter dois computadores, tablets, smartfones, telemóveis ligados à Internet para comunicar da forma que achar mais conveniente. Na perspetiva de Tornero (2007, p. 86), “[...] uma informação digital capaz de representar, de forma cada vez mais rápida e definida, a totalidade do mundo (fenomenológico ou não) que compõe a realidade planetária”.

Segundo o autor, as tecnologias telemáticas e informáticas permitem anular as distâncias, ou seja, permitem tornar próximo aquilo que na realidade e objetivamente 
pode se encontrar distante, perto ou em qualquer lado. Elas permitem obter informação fácil e rápida, interagir com outras pessoas e com o mundo, partilhar, agir e criar a realidade para o próprio e para todas as pessoas que partilharem essa informação. Para Negroponte (1996, p. 229),

A persona de uma máquina torna-se divertida, calmante, utilizável, amistosa e possuidora de espírito menos "mecânico". Amansar um novo computador pessoal assemelhar-se-á mais ao treino de um cachorro. Poderemos comprar módulos de personalidade que incluam o comportamento e o estilo de vida de personagens fictícias.

Segundo o autor, o computador passa a ser um instrumento de trabalho divertido, amigável e mais personalizado, mais adequado aos gostos, desejos e necessidades de seus utilizadores. Nesse sentido, os computadores passam a ser parte integrante da construção da realidade, através da realidade virtual. Como podemos verificar na explicação de Corrêa (2008, p. 309): "Se retomarmos os autores precursores do tema, a exemplo de Alvin Tofler, Nicholas Negroponte e até mesmo Bill Gates já em meados dos anos 1990, podemos constatar que o espaço das novas mídias esteve separado do mundo físico, real".

Neste texto, pudemos verificar que nos anos 1990 o mundo da comunicação estava separado do mundo físico, ou seja, a comunicação acontecia nos meios tradicionais, como jornais, revistas, rádio, televisão, organização de eventos, outdoors, relações públicas, entre outros, e as experiências digitais aconteciam de uma forma fictícia e ainda pouco operacionalizada, algo distante, fazendo parte de um mundo ficcionado. Assim como, prosseguindo Corrêa (2008, p. 114) afirma que "Salaverría entende por hipertextualidade a capacidade de conectar diversos textos digitais entre si. Define a multimedialidade como a capacidade outorgada pelo suporte digital de combinar em uma mesma mensagem pelo menos dois dos três seguintes elementos: texto, imagem e som" (BERTOCCHI, 2006, p. 57).

Segundo esse autor, as formas comunicacionais do ciberespaço são hipertextualidade, que tem a faculdade de construir significado com diferentes textos digitais; a multimedialidade que projeta simultaneamente texto, imagem e som e interatividade, permitindo a troca, partilha e construção da própria realidade em simultâneo com seu aparecimento instantâneo em qualquer parte do planeta (Figura 1). 
Figura 1 - A comunicação eletrônica e digital

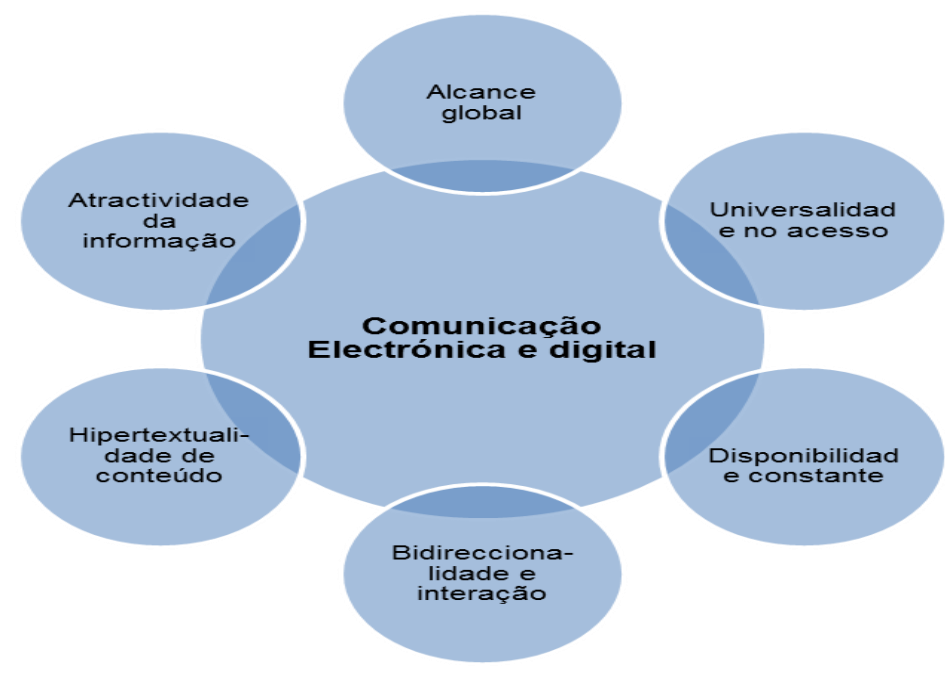

Fonte: adaptado de Corrêa (2008, p. 314).

Os aspectos mais relevantes da comunicação eletrônica e digital passam pela capacidade de estar em todo lado, em qualquer parte do mundo; utilizada por qualquer pessoa de uma forma universal e sem qualquer limitação, a qualquer hora do dia ou da noite; tornando possível interagir, participar, comunicar bidirecionalmente, fator fundamental para a eficiência na comunicação e com a possibilidade de inclusão de animações, sons e multimídia que proporcione uma maior interatividade e conectividade contribuindo para uma mais eficiente compreensão e eficiência comunicacional. No entendimento dos autores Vieites e Veloso (2008, p. 37),

Atualmente, existe um grande debate na Internet sobre a necessidade de garantir a privacidade dos seus utilizadores, existindo duas posturas: a primeira, partidária de uma intervenção por parte dos governos (defendida principalmente pelos países da União Europeia, que já dispõem de um marco jurídico bastante restrito nesta matéria), e a segunda, que defende a autorregulação por parte das empresas e organizações que atuam na Internet (postura dos EUA, que defende o desenvolvimento de um código ético que deve ser respeitado pelas empresas).

Hoje, segundo o autor, assistimos a um conjunto de preocupações e interrogações sobre a necessidade de regulamentação, legislação ou normalização e as melhores formas para proteger e preservar, por exemplo, os direitos de autor, direitos das marcas, defesa da privacidade, entre outros aspetos relativos à proteção de dados pessoais ou organizacionais.

Outro fator relevante é a relação dos meios de comunicação digital com a realidade e, sobre isso, Beneyto (2002, p. 55) afirma: “A la pérdida real de un espacio 
también real, sigue inevitablemente el anhelo de crear espacios imaginarios que los sustituyan. A medida que el espacio real se va agotando, crece la necesidad de sucedáneos virtuales".

Os espaços de comunicação reais e virtuais, como diz o autor, são conceitos que não se podem dissociar, e são complementares e indissociáveis na medida em que se difundem reciprocamente, pois, à medida que o espaço real se esgota, cresce a necessidade de construir espaços virtuais.

Atualmente, os espaços comunicacionais virtuais e reais acontecem de forma simultânea e constante, na medida em que ambas contribuem para definir, estruturar e consolidar a interatividade e participação do todo individual e coletivo.

\section{Considerações finais}

A comunicação é a ação de partilhar, de pôr em comum, de reduzir incertezas, de exteriorizar, comungar ideias, sentimentos, atitudes, opiniões, e, dessa forma, obter o retorno da informação (feedback). Todavia, o aspecto mais importante é a compreensão mútua, pois ela permite estabelecer uma relação recíproca de entendimento.

A partir dos anos 1990 entramos na era da individualização dos media, em que cada pessoa pode participar da construção de informações e cada um pode ser um todo comunicativo.

No entanto, comunicar eficientemente significa também construir a realidade, influenciando os outros através da transmissão de mensagens que vão ao encontro das necessidades humanas. O segredo da comunicação eficiente reside nos "actores sociais" enquanto indivíduos ou organizações capazes de se compreenderem mutuamente e gerar sinergias úteis aos indivíduos e à comunidade.

Os meios de comunicação social, hoje, constroem um conjunto de sensações, emoções, sentimentos coletivos, os quais as pessoas apenas aceitam sem questionar, e criam imaginários coletivos sobre a realidade. Dessa forma, mesmo com as tecnologias da comunicação, é necessário um esforço acrescido, pois não se chega a separar o acessório do essencial, é preciso ser criativo e inovador na plataforma individual de perceber o mundo e, assim, ser mais ativo e menos reativo perante a realidade. 
A comunicação eletrônica e digital é cada vez mais uma excelente forma de comunicar, já que é eficiente em termos de velocidade de processamento, facilidade de utilização e é extremamente econômica, pois basta ter dois computadores ligados à Internet para comunicar da forma que achar mais conveniente.

Em síntese, a comunicação e seus meios de comunicação, nas suas dinâmicas individuais, coletivas, reais e virtuais, são um tema deveras interessante, mas também demasiado complexo, dessa forma, ficam algumas ideias e considerações para continuar a estudar e desenvolver o assunto no futuro.

\section{REFERÊNCIAS}

BAUDRILLARD, J. A sociedad de consumo. Lisboa: Ed. 70, 1995.

BENEYTO, J. V. La ventana global. Santiago de Compostela: Generales, 2002.

CORRÊA, E. S. Reflexões para uma epistemologia da comunicação digital. In: Actas do $5^{\circ}$ Congresso da Associação Portuguesa de Ciências da Comunicação. Braga, 2008 .

GONZÁleZ, M. J. D.; OLMEDO, C. A.; HeRRERO, F. E.; CECILIA, J. M. G.; BAZZANI, E. M. El uso de Internet para acceder a los medios de comunicación colectiva. Resultados y conclusiones de la investigación aplicada en la ciudad de Segovia, 2004

NAFRÍA, J .M. D. La Caverna de las tecnologías de la información. In: ESQUIROL, J. M. (Ed.) Tecnología, ética y futuro. Bilbao: Desclée De Brouwer, 2001. p. 149-161.

FERNANDES, A. J. Métodos para elaboração de trabalhos académicos e científicos. Porto: Porto Editora, 1994.

HELDER, B. Jornalismo electrónico. Coimbra: Ed. Minerva, 2000.

JENNINGS, B. Critical Communication Challenges for the New Century. Journal of Communication, v. 54, n. 3, p. 389-401, 2004.

KERCKHOVE, D. A pele da cultura. Lisboa: Relógio d’Água, 1997.

LIPOVETSKY, G. A era do vazio. Lisboa: Relógio d'Água, 1983. 
LITTLEJOHN, S.W. Fundamentos teóricos da comunicação humana. Rio de Janeiro: Ed. Guanabara, 1998.

MCCHESNEY, R. W. Critical communication research at the crossroads. Journal of communication, v. 43, n. 4, p. 98-104, 1993.

NEGROPONTE, N. Ser digital. Lisboa: Ed. Caminho, 1996.

ROBERT, L. S. A critical look at critical analysis. Journal of communication, v. 33, n. 3, p. 262-269, 1986.

SOUSA, H.; SANTOS, L. A. RTP e Serviço Público, Um Percurso de inultrapassável dependência e contradição. In: PINTO, M. et. al. A televisão e a cidadania, contributos para o debate sobre o serviço público. Braga, Departamento de Ciências da Comunicação da Universidade do Minho, 2003.

TORNERO, J. M. P. (Coord.) Comunicação e educação na sociedade da informação. Porto: Ed. Porto Editora, 2007.

VIEITES, Á. G.; ESPIÑEIRA, M. V. Marketing na Internet e nos meios digitais interactivos. Porto: Ed. Vida Económica, 2008.

Recebimento dos originais: 07/05/2014

Aceitação para publicação: 25/08/2014 